\title{
Disabled homolog 2 interactive protein functions as a tumor suppressor in osteosarcoma cells
}

\author{
JIANAN HE ${ }^{1,5}$, SHUAI HUANG ${ }^{2}$, ZHENHUA LIN $^{3}$, JIQIN ZHANG $^{4}$, JIALIN SU ${ }^{4}$, WEIDONG JI ${ }^{4}$ and XINGMO LIU ${ }^{1}$ \\ ${ }^{1}$ Department of Orthopaedic Surgery, The Sixth Affiliated Hospital of Sun Yat-sun University, Guangzhou, \\ Guangdong 510655; ${ }^{2}$ Department of Orthopaedic Surgery, The First Affiliated Hospital of Sun Yat-sen University, Guangzhou, \\ Guangdong 510080; ${ }^{3}$ Department of Orthopaedic Surgery, The People's Hospital of Guangxi Zhuang Autonomous Region, \\ Nanning, Guangxi 530021; ${ }^{4}$ Center for Translational Medicine, The First Affiliated Hospital of Sun Yat-sen University, \\ Guangzhou, Guangdong 510080; ${ }^{5}$ Department of Interventional Radiology, The Fifth Affiliated \\ Hospital of Sun Yat-sun University, Zhuhai, Guangdong 519000, P.R. China
}

Received April 2, 2016; Accepted June 16, 2017

DOI: $10.3892 / \mathrm{ol} .2018 .8776$

\begin{abstract}
The disabled homolog 2 interactive protein (DAB2IP) gene is a member of the family of Ras GTPases and functions as a tumor suppressor in many types of carcinoma; however, its function in osteosarcoma remains unclear. The aim of the present study was to determine the function of DAB2IP in osteosarcoma and normal bone cells in vitro. The expression of DAB2IP protein was assessed in osteoblast and osteosarcoma cell lines by western blot analysis. The effects of DAB2IP expression on cell proliferation, colony formation, apoptosis, cell cycle, and cell migration and invasion were evaluated by in vitro studies. DAB2IP expression was lower in osteosarcoma cell lines than in normal osteoblast cell lines. DAB2IP expression affected cell proliferation, apoptosis and cell cycle distribution. In addition, DAB2IP inhibited the migration and invasion of osteosarcoma and normal osteoblast cells. Therefore, DAB2IP may function as a tumor suppressor in osteosarcoma cell lines by inhibiting cell proliferation and invasion.
\end{abstract}

\section{Introduction}

Osteosarcoma is the most common type of primary bone malignancy and is frequently diagnosed in children and adolescents (1). A large proportion of patients diagnosed with

Correspondence to: Dr Xingmo Liu, Department of Orthopaedic Surgery, The Sixth Affiliated Hospital of Sun Yat-sun University, 26 Yuancun 2nd Road, Guangzhou, Guangdong 510655, P.R. China E-mail: liuxingmo@163.com

Professor Weidong Ji, Center for Translational Medicine, The First Affiliated Hospital of Sun Yat-sen University, 58 Zhongshan 2nd Road, Guangzhou, Guangdong 510080, P.R. China

E-mail:wdji2008@163.com

Key words: disabled homolog 2 interactive protein, osteosarcoma, cell proliferation, cell migration and invasion osteosarcoma will develop distant metastasis (2). Owing to the development of multidisciplinary therapy, the mortality rate for patients with osteosarcoma has been decreasing in recent years. Nevertheless, patients continue to exhibit a high risk of metastasis and/or recurrence $(1,2)$. Previous studies have indicated that several genetic aberrations are associated with tumor initiation and osteosarcoma progression $(3,4)$. Thus, identifying the underlying mechanisms that lead to the development and progression of osteosarcoma is crucial.

Disabled homolog 2-interacting protein (DAB2IP), located at chromosome location 9q33.1-q33.3, is a member of the Ras GTPase family (5-7). Downregulation of DAB2IP is frequently detected in various types of human cancer, including gastrointestinal cancer, breast tumor, prostate carcinoma, pulmonary tumor, pancreatic cancer, hepatocellular cancer and medulloblastoma (6,8-16). Loss of DAB2IP expression may facilitate cell proliferation and restrain cancer cell metastasis through several pathways, including Ras-extracellular-related kinase, apoptosis signal-regulating kinase 1 (ASK1)-c-Jun $\mathrm{N}$-terminal kinase (JNK) and phosphoinositide-3 kinase (PI3K)-Akt (6,7,17-19). DAB2IP suppression may induce resistance to ionizing radiation and chemoresistance in prostate cancer and nonmuscle invasive bladder cancer (20-23). Furthermore, a role is hypothesized for DAB2IP in normal brain development and vascular inflammation (24-29), and the loss of DAB2IP may promote the epithelial-mesenchymal transition (EMT) and induce cancer stem cells to facilitate colorectal carcinoma progression and metastasis $(16,30)$.

Although its role as a potent tumor suppressor in several carcinomas has been demonstrated (8-16), the expression and biological function of DAB2IP in osteosarcoma remain uncharacterized. In the present study, the endogenous expression of DAB2IP and its role in osteosarcoma cell lines were assessed, as was the effect of DAB2IP expression on cell progression and motility in osteosarcoma cells.

\section{Materials and methods}

Cell lines and cell culture. The osteosarcoma MG-63 and HOS cell lines an osteoblast hFOB 1.19 cell line and the 
human embryonic kidney 293T cells were all purchased from the Cell Bank of Type Culture Collection of Chinese Academy of Sciences (Shanghai, China). MG-63, HOS and 293T cells were cultured in high-glucose Dulbecco's modified Eagle's medium (DMEM; Thermo Fisher Scientific, Inc., Waltham, MA, USA). A DMEM/Ham's F12 (Thermo Fisher Scientific, Inc.) mix was used to culture hFOB 1.19 cells. Media contained $10 \%$ fetal bovine serum (FBS; Thermo Fisher Scientific, Inc.) and antibiotics, including $100 \mathrm{U} / \mathrm{ml}$ penicillin and $100 \mu \mathrm{g} / \mathrm{ml}$ streptomycin. Cells were cultured at $37^{\circ} \mathrm{C}$ and $5 \% \mathrm{CO}_{2}$ in a humidified incubator.

Plasmid construction, lentivirus infection and establishment of stably transfected cell lines. The pLEX DAB2IP, pLEX Control, DAB2IP short hairpin (sh)RNA pLKO.3G and scrambled shRNA pLKO.3 G plasmids were gifts from Professor Wang Min (Yale University, New Haven, CT, USA). The DAB2IP shRNA sequence was as follows: 5'-TAAAAAAAGCCTTAT TTACCTAGTGCAAACTCGAGTTTGCACTAGGTAAAT AAGGC-3'. The scrambled shRNA sequence was as follows: 5'-GACTATCATATGCTTACCGT-3'. The target vectors $(1.2 \mu \mathrm{g})$ were mixed with $1.2 \mu \mathrm{g}$ lentivirus packaging helper plasmids pCMV-dR8.2 (Addgene, Cambridge, MA, USA) and $0.6 \mu \mathrm{g}$ pCMV-VSVG plasmids (Addgene), and the mixed vectors were diluted in $120 \mu \mathrm{l}$ Opti-MEM (Thermo Fisher Scientific, Inc.). Following this, $5 \mu 1$ P3000 Reagent was added (Invitrogen; Thermo Fisher Scientific, Inc.) to the final volume of $125 \mu 1$. Meantime, $7.5 \mu$ l Lipofectamine ${ }^{\circledR} 3000$ reagent (Invitrogen; Thermo Fisher Scientific, Inc.) was diluted into Opti-MEM medium to a final volume $125 \mu \mathrm{l}$. Then, the diluted vectors and diluted Lipofectamine 3000 reagent were mixed, and incubated for $15 \mathrm{~min}$ at room temperature. The complex was added into $\sim 70 \%$ confluence $293 \mathrm{~T}$ cells in the 6 -wells plate. Viruses were harvested $48 \mathrm{~h}$ after transfection and subsequently used to infect HOS and hFOB 1.19 cells, with puromycin (Thermo Fisher Scientific, Inc.) used to select the positive clones. The stable cell lines obtained were correspondingly designated as HOS pLEX DAB2IP, HOS pLEX Control; hFOB 1.19 DAB2IP shRNA, hFOB 1.19 scrambled shRNA; hFOB 1.19 DAB2IP shRNA-pLEX DAB2IP and hFOB 1.19DAB2IP shRNA-pLEX. The effect of the overexpression and knockdown on DAB2IP were assessed by western blot analysis.

Western blot analysis. Cultured MG-63, HOS and hFOB 1.19 cells were collected and washed twice with $1 \mathrm{ml}$ of PBS. Following cell lysis with protein lysis buffer $(50 \mathrm{mM}$ Tris (pH 7.4), $2 \mathrm{mM}$ EDTA, $150 \mathrm{mM} \mathrm{NaCl}, 1 \mathrm{mM} \mathrm{Na} \mathrm{VO}_{4}$, $1 \%$ Triton X-100, $20 \mathrm{mM} \mathrm{NaF}, 10 \mathrm{mM} \mathrm{Na}_{4} \mathrm{P}_{2} \mathrm{O}_{7}, 10 \mathrm{mg} / \mathrm{ml}$ aprotinin), cells were collected and centrifuged at 4,000 x g for $15 \mathrm{~min}$ at $4^{\circ} \mathrm{C}$. Protein concentration was quantified using the Bradford assay (Bio-Rad Laboratories, Inc., Hercules, CA, USA). Equivalent quantities of protein (20 $\mu \mathrm{g} /$ lane) were resolved using SDS-PAGE on an $8 \%$ gel and transferred to polyvinylidene fluoride membranes. Membranes were blocked using PBS with $0.1 \%$ Tween 20 (PBST) containing $5 \%$ skimmed milk powder for $2 \mathrm{~h}$ at room temperature, and incubated with primary antibodies against DAB2IP (cat. no. 48-7300; Invitrogen, Thermo Fisher Scientific, Inc.; 1:1,000) and GADPH (cat. no. 2118; Cell Signaling Technology, Danvers, MA, USA; 1:1,000) overnight at $4^{\circ} \mathrm{C}$. Subsequent to washing with PBST, the membranes were incubated $2 \mathrm{~h}$ at room temperature with goat anti-rabbit immunoglobulin $\mathrm{G}$ secondary antibodies conjugated with horseradish peroxidase (cat. no. 7074; Cell Signaling Technology; 1:1,000).

Cell proliferation assay. An MTS cell proliferation assay was performed using the AQueous One solution Cell Proliferation Assay kit (Promega Corporation, Madison, WI, USA) to assess cell proliferative activity. HOS, hFOB 1.19 and hFOB 1.19 DAB2IP shRNA cells were plated at density of 10,000 cells per well in 96-well plates. After 0, 24, 48, 72 or 96 h, $20 \mu \mathrm{l}$ of MTS was added into each well, and incubated at $37^{\circ} \mathrm{C}$ for $3 \mathrm{~h}$. To measure the absorbance values, a microplate reader was used, set at $490 \mathrm{~nm}$. Three independent experiments were performed.

Colony formation assay. Approximately 1,000 HOS, hFOB 1.19 or hFOB 1.19 DAB2IP shRNA cells were seeded in a $35-\mathrm{mm}$ dish and incubated for 10 days at $37^{\circ} \mathrm{C}$. Formed colonies were then fixed with $100 \%$ methanol for $20 \mathrm{~min}$ and stained with $0.1 \%$ crystal violet for $30 \mathrm{~min}$ at room temperature. The number of colonies composed of $>50$ cells per dish was counted under a light microscope. Each experiment was repeated three times.

Cell apoptosis assay. Osteosarcoma cell apoptosis following lentiviral transduction was examined using an Annexin V/propidium iodide (PI) kit; osteoblast apoptosis was detected using an APC/PI kit (both eBioscience; Thermo Fisher Scientific, Inc.). According to the manufacturer's protocol, cells were collected and resuspended in $200 \mu \mathrm{l}$ of $1 \mathrm{X}$ binding buffer at a concentration of $1 \times 10^{6}$ cells and stained with $5 \mu 1$ annexin V-fluorescein isothiocitrate or APC dye, followed by staining with $5 \mu \mathrm{l} \mathrm{PI}$. The proportion of cells undergoing apoptosis was analyzed by a flow cytometer (eBioscience; Thermo Fisher Scientific, Inc.), and the results were analyzed using FlowJo 7.6.2 software (Tree Star, Inc., Ashland, OR, USA). Three independent experiments were performed.

Cell cycle assay. HOS, hFOB 1.19 and hFOB 1.19 DAB2IP shRNA cells $\left(1 \times 10^{6}\right.$ cells $/ 100-\mathrm{mm}$ dishes $)$ were plated in the appropriate FBS-free medium and incubated for $24 \mathrm{~h}$ at $37^{\circ} \mathrm{C}$. Following a further $24 \mathrm{~h}$ of incubation at $37^{\circ} \mathrm{C}$ in medium containing FBS, cells were collected and resuspended in $500 \mu \mathrm{l}$ of cold PBS, then stained with $25 \mu \mathrm{l}$ of PI in the dark for $30 \mathrm{~min}$ at $4^{\circ} \mathrm{C}$. Cells were analyzed for cell cycle distribution using a flow cytometer (BD Biosciences, Franklin Lakes, NJ, USA). ModFit LT3.1 software (Verity Software House, Inc., Topsham, ME, USA) was used to analyze the results. Each experiment was repeated three times.

Migration and invasion assays. Cell migration and invasion rates were determined as described in previously published methods (31-33) in HOS, hFOB 1.19 and hFOB 1.19 DAB2IP shRNA cells. To study migration, $2 \times 10^{4}$ cells were seeded into each well of a 96-well plate. When cells had reached $80-90 \%$ confluence, a wound was generated using the Cellplayer 96-well Woundmaker (Essen BioScience, Inc., Ann Arbor, MI, USA). The images of cells were automatically acquired every $2 \mathrm{~h}$ for $24 \mathrm{~h}$ using the Incucyte LiveCell Imaging system (Essen BioScience, Inc.). 
To study invasion, a scratch was made by using the Cellplayer 96-well Woundmaker, when cells had reached $80-90 \%$ confluence. Next, the wound was covered with $50 \mu 1$ of Matrigel solution ( $1 \mathrm{mg} / \mathrm{ml}$ Matrigel in PBS) that was allowed to set for $1 \mathrm{~h}$ at $37^{\circ} \mathrm{C}$. Appropriate growth medium $(100 \mu \mathrm{l})$ was added and representative images were recorded at $2 \mathrm{~h}$ intervals for the duration of the experiment $(24 \mathrm{~h})$. All images were processed using the IncuCyte ${ }^{\mathrm{TM}}$ software package version 20151.1 (Essen BioScience, Inc.) to measure cell migration and invasion by obtaining the relative wound density.

Statistical analysis. Data are presented as the mean \pm standard deviation. Comparisons between two groups were performed using unpaired Student's t-tests. Multiple group comparison was performed using one-way analysis of variance. And the post hoc test was Bonferroni correction. $\mathrm{P}<0.05$ was considered to indicate a statistically significant difference. Statistical analyses were performed using the commercially available packages PASW statistics 18.0 (SPSS Inc, Chicago, IL, USA) and GraphPad Prism 6 (GraphPad Software, La Jolla, CA, USA).

\section{Results}

DAB2IP is downregulated in osteosarcoma cell lines. Western blotting was performed to assess endogenous DAB2IP expression levels in the normal human osteoblast cell line, hFOB 1.19, and the human osteosarcoma MG63 and HOS cell lines. DAB2IP expression was downregulated in the osteosarcoma cell lines compared with the normal osteoblast cell line (Fig. 1A).

To examine the effects of DAB2IP expression in osteosarcoma, DAB2IP was overexpressed or silenced in HOS cells. Marked differences in DAPB2IP expression were observed between the pLEX control and pLEX DAB2IP cells (Fig. 1B). The shRNA-mediated interference of DAB2IP (Fig. 1C) and its expression (Fig. 1D) through lentivirus infection were confirmed.

DAB2IP inhibits cell proliferation and colony formation. MTS and colony formation assays were performed to determine the effects of ectopic DAB2IP expression on cell growth in HOS pLEX DAB2IP cells and controls (Fig. 2). As demonstrated in Fig. 2A, the proliferation of HOS cells transfected with pLEX DAB2IP was significantly reduced compared to HOS cells transfected with a vector control. By contrast, it was observed that the proliferation was significantly increased when DAB2IP expression was knocked down in hFOB cells (Fig. 2B), and the restoration of DAB2IP expression in DAB2IP-shRNA-treated hFOB cells suppresses osteoblast proliferation (Fig. 2C). The number of colonies formed by HOS cells transfected with pLEX DAB2IP was decreased compared with the control group (Fig. 2D). Similar to the proliferation results, the colony formation abilities of the DAB2IP-shRNA-treated cells was significantly increased compared with those treated with scrambled shRNA (Fig. 2E), and restoring DAB2IP expression suppressed the colony formation ability of the osteoblast cells (Fig. 2F).

DAB2IP promotes bone cell apoptosis and increases G0/G1 phase distribution. To determine whether DAB2IP could induce apoptosis in osteosarcoma cells, the cell cycle distribution of HOS pLEX and HOS pLEX DAB2IP cells was evaluated by flow cytometry. As presented in Fig. 3A, the rate of apoptosis in HOS pLEX DAB2IP cells was significantly higher than control HOS pLEX cells $(6.804 \pm 1.051 \%$ vs. $1.717 \pm 0.208 \%$, respectively). Similarly, upregulation of DAB2IP induced apoptosis in pLEX-DAB2IP cells compared with control cells $(5.291 \pm 0.808 \%$ vs. $1.038 \pm 0.277 \%$, respectively; Fig. 3B). These findings suggested that DAB2IP induces cell apoptosis in osteosarcoma cells and osteoblasts.

In order to further assess the mechanism by which DAB2IP affects cell proliferation, cell cycle progression was determined using flow cytometry. As shown in Fig. 3B, a significantly greater proportion of HOS pLEX DAB2IP cells were in the G0/G1 phase compared with the control cells $(47.543 \pm 1.810 \%$ vs. $39.940 \pm 1.628 \%$, respectively; Fig. 4A). By contrast, downregulation of DAB2IP expression in hFOB 1.19 cells resulted in a greater proportion of cells in S-phase than the hFOB 1.19 Scrambled shRNA cells $(47.893 \pm 2.409 \%$ vs. $37.277 \pm 2.247 \%$, respectively; Fig. 4B). However, the G0/G1 phase distribution of pLEX DAB2IP cells was higher than pLEX control cells $(43.097 \pm 5.997 \%$ vs. $31.450 \pm 3.922 \%)$, with fewer cells in S phase (39.613 $\pm 3.964 \%$; Fig. 4C).

DAB2IP suppresses cell migration and invasiveness. Given that DAB2IP can inhibit the proliferation of osteosarcoma and normal osteoblasts, its function on cell motility was assessed. The effect of DAB2IP on cell migration was examined using a scratch wound-healing assay, with cell migration measured by determining the relative wound density. The migration rate of HOS pLEX DAB2IP cells was significantly lower than that observed for HOS pLEX control cells (Fig. 5A). However, downregulation of DAB2IP expression in hFOB 1.19 immortalized human osteoblasts induced migration (Fig. 5B). hFOB 1.19 DAB2IP shRNA cells exhibited significantly reduced cell migration compared with control transfected cells (Fig. 5C).

The effect of DAB2IP on the invasive potential of osteosarcoma and normal osteoblasts was then investigated. As presented in Fig. 6A, the upregulation of DAB2IP could inhibit the osteosarcoma HOS cell invasion into Matrigel, whereas the downregulation of DAB2IP in hFOB 1.19 cells promoted cell invasion through the Matrigel barrier, with restoration of DAB2IP expression suppressing cell invasion when compared with hFOB 1.19 DAB2IP shRNA cells (Fig. 6B and C, respectively). Collectively, these results demonstrated that DAB2IP inhibits cell migration and invasion in osteosarcoma cell lines.

\section{Discussion}

In the present study, a lentivirus transfection-mediated approach was used to investigate the role of DAB2IP in osteosarcoma cells and osteoblasts. Overexpression of DAB2IP led to a significant change in proliferation, apoptosis, cell cycle distribution, migration and invasion in the HOS cell line. Downregulation of DAB2IP in hFOB 1.19 cells confirmed that it promoted proliferation, with restoration of its expression resulting in the suppression of cell growth.

DAB2IP is a member of the Ras GTPase family that was originally identified in prostate cancer (5). To date, its downregulation has been observed in a range of types of 
A

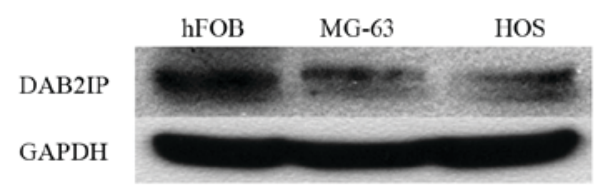

$\mathrm{C}$

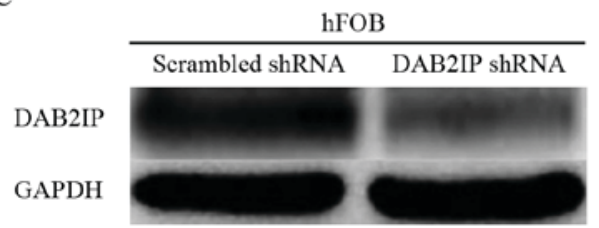

B

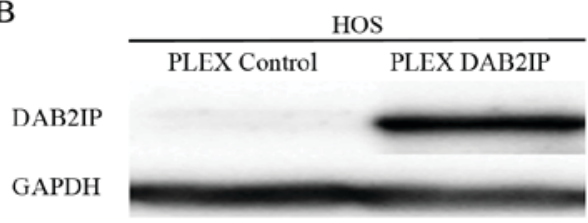

$\mathrm{D}$

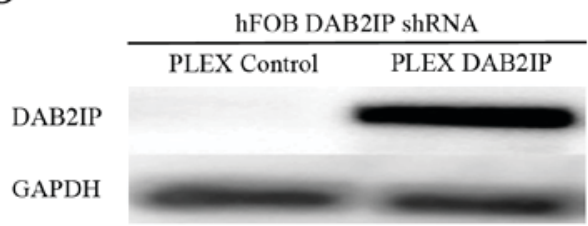

Figure 1. Expression of DAB2IP in osteoblasts and osteosarcoma cells. (A) DAB2IP expression in the immortalized normal human osteoblast hFOB 1.19 cell line, and the human osteosarcoma MG63 and HOS cell lines. (B) DAB2IP expression in HOS cells following transfection with pLEX DAB2IP. (C) DAB2IP expression in hFOB 1.19 cells following shRNA silencing. (D) DAB2IP expression in hFOB 1.19 DAB2IP shRNA cells following transfection with pLEX DAB2IP. GAPDH was used as a loading control. DAB2IP, disabled homolog 2 interactive protein; shRNA, short hairpin RNA; pLEX DAB2IP, plasmid containing DAB2IP.

A

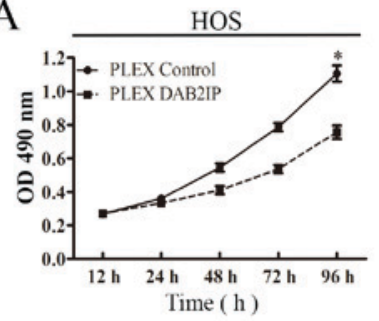

B

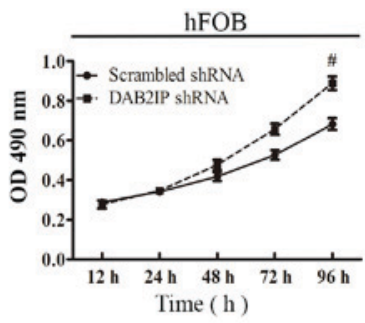

$\mathrm{C}$

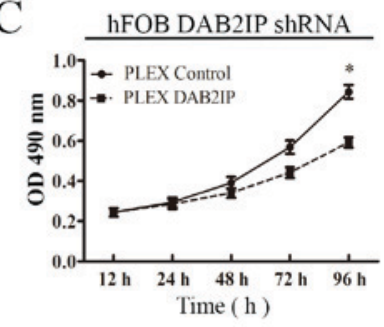

$\mathrm{D}$
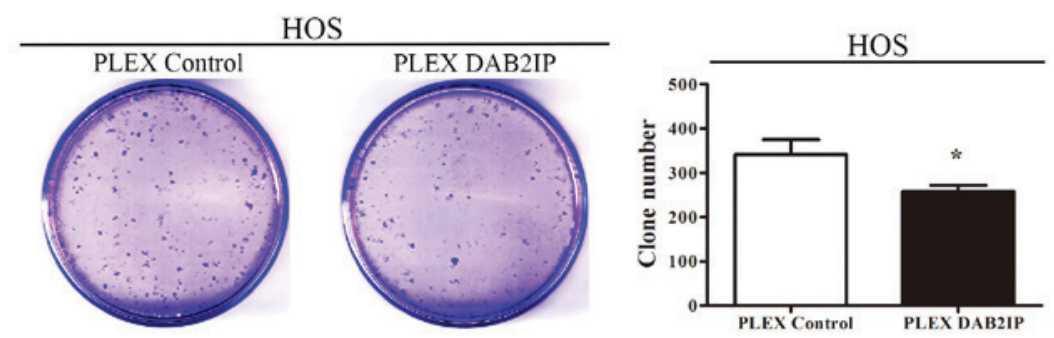

E

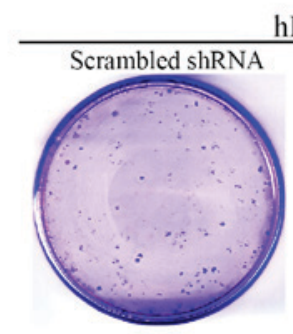

hFOB
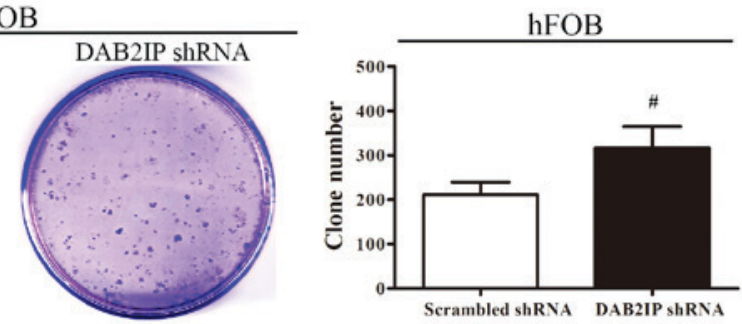

F hFOB DAB2IP ShRNA
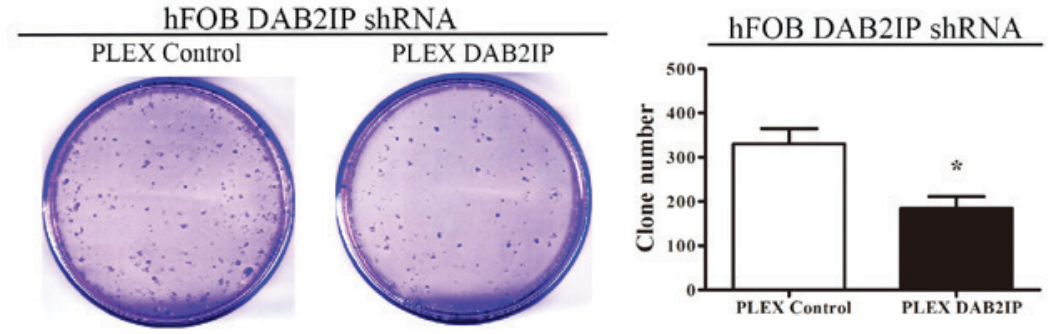

Figure 2. Effect of DAB2IP overexpression and silencing on the in vitro cell proliferation and colony formation of osteosarcoma and osteoblast cells. Effect of DAB2IP on the proliferation of (A) HOS, (B) hFOB 1.19 and (C) hFOB 1.19 pLEX DAB2IP cells, as determined by an MTS cell proliferation assay. Effect of DAB2IP on colony formation by (D) HOS, (E) hFOB 1.19 and (F) hFOB 1.19 pLEX DAB2IP cells. "P<0.05, comparing HOS PLEX control cells with HOS PLEX DAB2IP cells in A and D. ${ }^{*} \mathrm{P}<0.05$, comparing hFOB Scrambled shRNA cells with hFOB DAB2IP shRNA cells in B and E. "P<0.05, comparing hFOB DAB2IP shRNA PLEX control cells with hFOB DAB2IP shRNA PLEX DAB2IP cells in C and F. DAB2IP, disabled homolog 2 interactive protein; shRNA, short hairpin RNA; OD, optical density; pLEX DAB2IP, plasmid containing DAB2IP. 
A

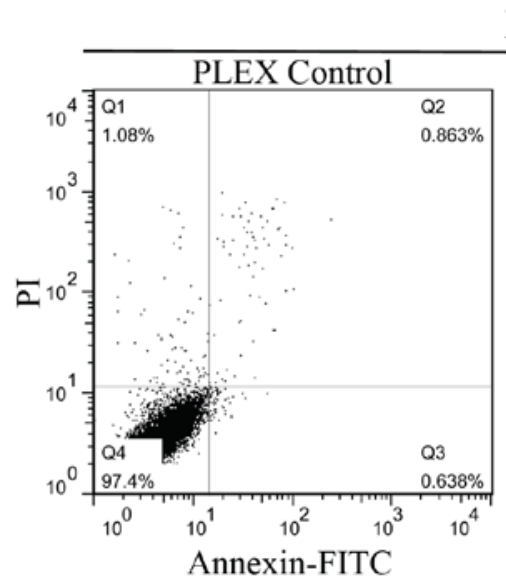

HOS
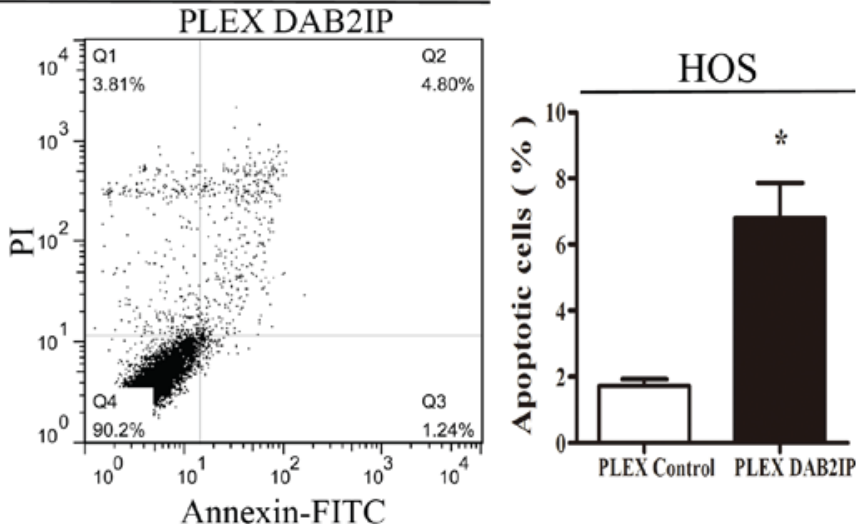

$\mathrm{B}$

hFOB DAB2IP shRNA
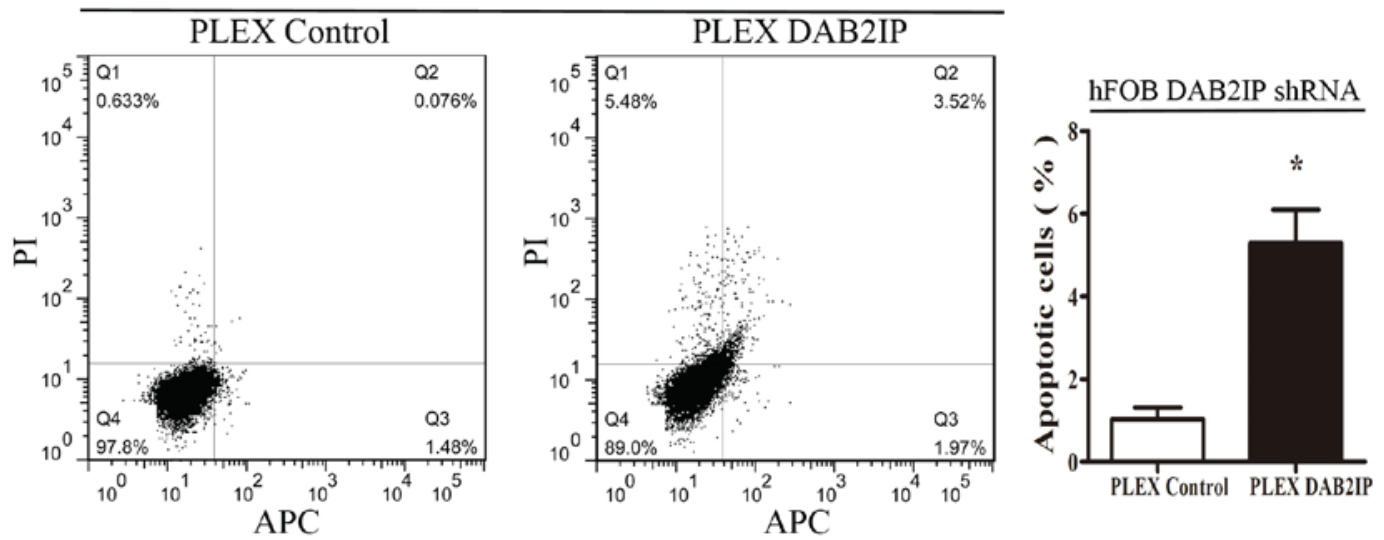

Figure 3. Effects of DAB2IP expression on apoptosis and cell cycle progression in osteosarcoma cells and normal osteoblasts. (A) Effect of DAB2IP expression on the apoptosis of HOS cells. Representative images are on the left and quantification on the right. (B) Effect of DAB2IP expression on apoptosis of human osteoblast hFOB 1.19 cell line as determined by an apoptosis assay. Representative images are shown on the left, and quantification is shown on the right. All results are representative of three independent experiments. " $\mathrm{P}<0.05$, comparing HOS PLEX control cells with HOS PLEX DAB2IP cells. "P<0.05, comparing hFOB DAB2IP shRNA PLEX control cells with hFOB DAB2IP shRNA PLEX DAB2IP cells. DAB2IP, disabled homolog 2 interactive protein; pLEX DAB2IP, plasmid containing DAB2IP; FITC, fluorescein isothiocyanate; shRNA, short hairpin RNA.

human malignancy, including in cancer of the prostate, breast, liver, pancreas, gastrointestinal tract and bladder (6,8-16). In addition, downregulation of DAB2IP gene expression, predominantly due to epigenetic modification, was associated with unfavorable tumor characteristics and outcomes in cancer of the prostate, bladder, gastrointestinal tract and liver $(8-11,34,35)$. Two genome-wide association studies of aggressive prostate cancer suggested that DAB2IP is a putative prostate tumor-suppressor gene (36). In the present study, differential DAB2IP expression was confirmed through western blot analysis, suggesting that DAB2IP may function as a tumor suppressor gene.

DAB2IP can facilitate the dissociation of 14-3-3 proteins from ASK1, leading to enhanced ASK1-JNK activation in response to tumor necrosis factor (TNF) (7). DAB2IP also associates with TNF receptor-associated factor 2 (TRAF2) and mediates TNF/TRAF2-induced ASK1-JNK activation while inhibiting I $\mathrm{B}$ kinase/nuclear factor $\kappa \mathrm{B}(\mathrm{NF}-\kappa \mathrm{B})$ signaling (24). Furthermore, DAB2IP induces G0/G1 cell cycle arrest and promotes apoptosis through suppression of the PI3K-Akt pathway accompanied with activating ASK-JNK signaling in prostate cancer cells (18). In the present study, DAB2IP expression was downregulated in osteosarcoma cell lines compared with normal human osteoblasts. Gain- and loss-of-function approaches were employed to investigate the effect of DAB2IP expression on cell-cycle distribution and apoptosis. Overexpression of DAB2IP led to an increased rate of apoptosis and induced G0/G1 cell cycle arrest, as reported in a previous study (18). Therefore, DAB2IP may inhibit cell growth by inducing apoptosis and inhibiting cell cycle progression.

The majority of osteosarcoma patients develop metastasis, and outcomes for these patients remain poor (37-39). Previous studies suggest that DAB2IP may regulate cancer cell metastasis $(13,15,16,19,40)$. A previous study revealed that loss of DAB2IP facilitated EMT, leading to prostate cancer metastasis via the GSK-3 $\beta$ - $\beta$-catenin signaling pathway (19). Min et al (41) identified that the epigenetic silencing of DAB2IP by EZH2 promoted tumorigenesis and distant metastasis by Ras and NF- $\kappa \mathrm{B}$ activation. Further previous studies 
A

HOS

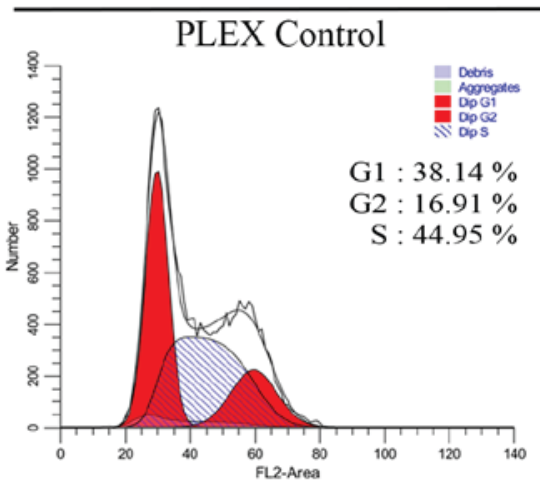

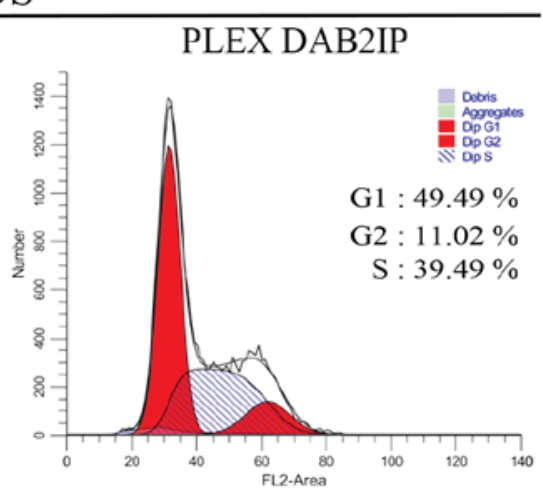

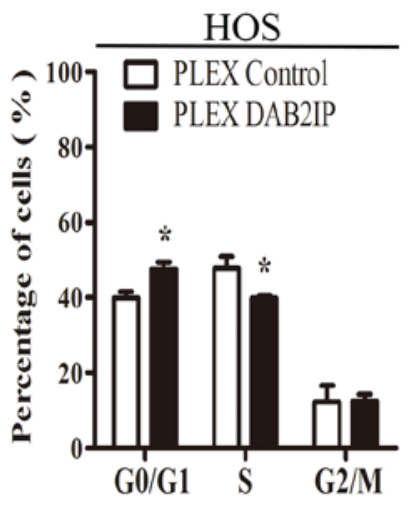

$\mathrm{B}$

hFOB

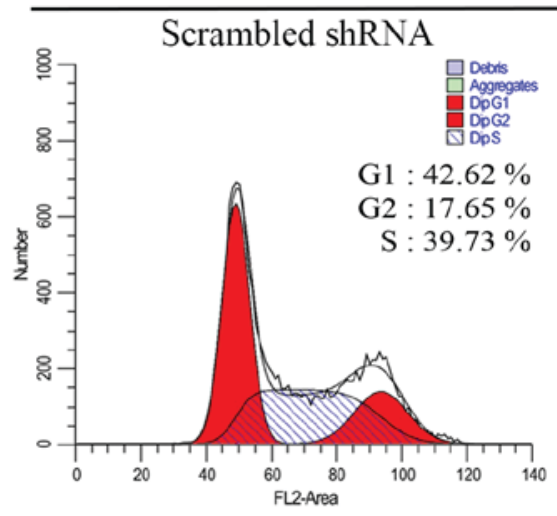

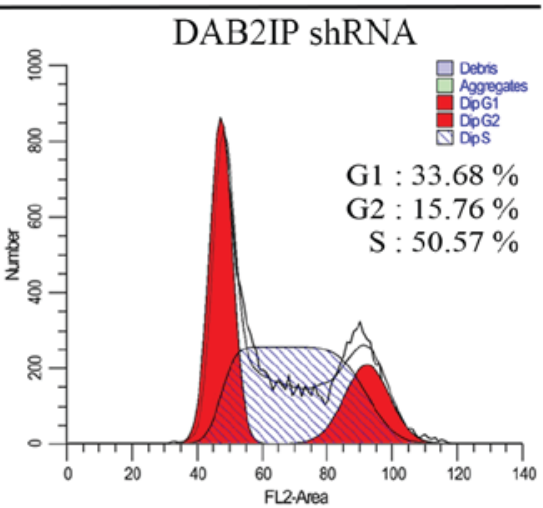

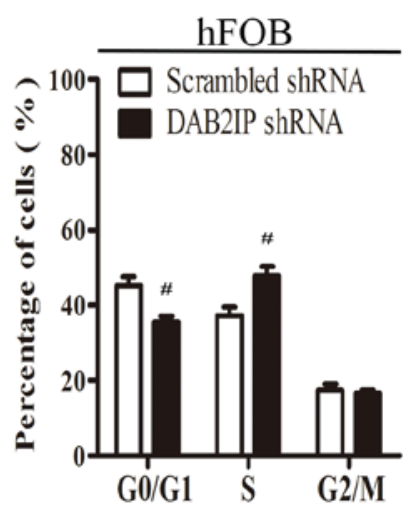

$\mathrm{C}$

hFOB DAB2IP shRNA
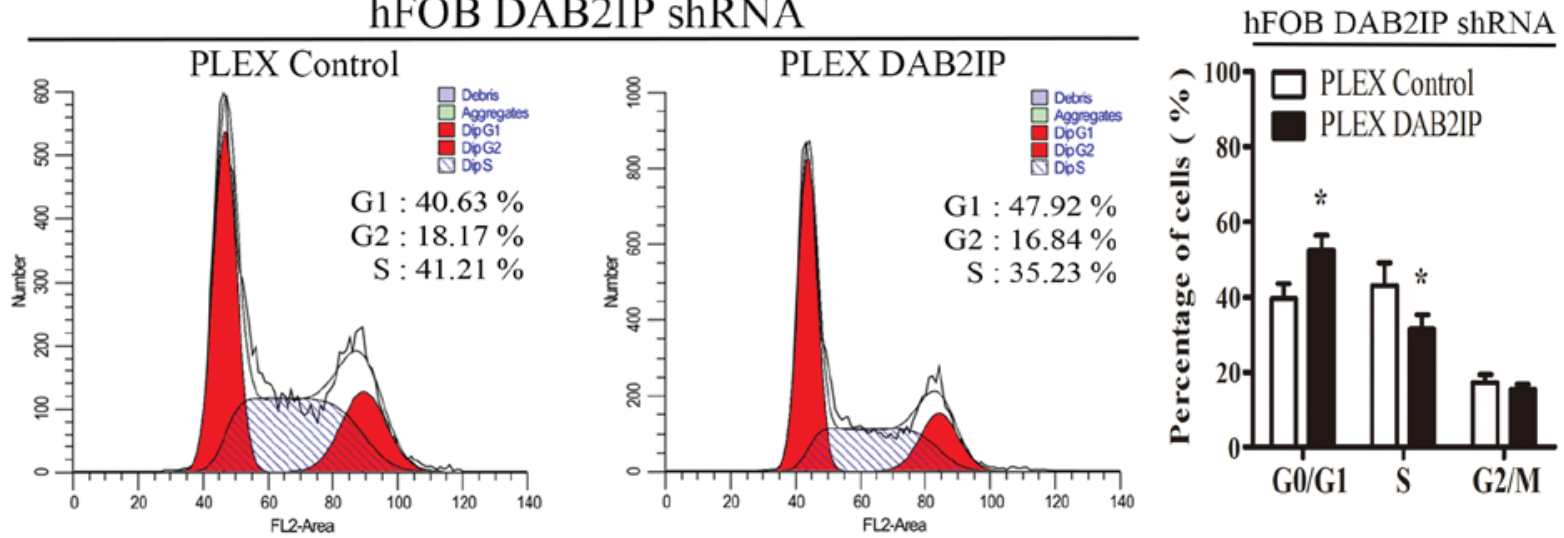

Figure 4. Effects of DAB2IP expression on the cell cycle distribution of osteosarcoma cells and normal osteoblasts. (A) Effect of DAB2IP expression on cell-cycle phase distribution of HOS osteosarcoma cells, as determined by flow cytometry. (B and C) Effect of DAB2IP expression on the cell-cycle phase distribution of hFOB 1.19 osteoblasts, as determined by flow cytometry. Representative images are on the left, and quantification on the right. All results are representative of three independent experiments. ${ }^{*} \mathrm{P}<0.05$, comparing HOS PLEX control cells with HOS PLEX DAB2IP cells. ${ }^{\#} \mathrm{P}<0.05$, comparing hFOB Scrambled shRNA cells with hFOB DAB2IP shRNA cells. ${ }^{*} \mathrm{P}<0.05$, comparing hFOB DAB2IP shRNA PLEX control cells with hFOB DAB2IP shRNA PLEX DAB2IP cells. DAB2IP, disabled homolog 2 interactive protein; shRNA, short hairpin RNA; shRNA, short hairpin RNA; pLEX DAB2IP, cells transfected with plasmid expressing DAB2IP.

revealed that DAB2IP could restrain tumor growth and metastasis by suppressing tumor angiogenesis, pre-metastatic niche formation and tumor EMT initiation via inhibition of vascular endothelial growth factor receptor 2-dependent signaling in the tumor niche (42). In the present study, an increase in DAB2IP expression in osteosarcoma cells significantly reduced cancer cell migration and invasion. The decreased expression of DAB2IP in osteoblasts enhanced their migration and invasion. Furthermore, the restoration of DAB2IP expression may suppress cell migration and invasion.

DAB2IP acts as a tumor suppressor in osteosarcoma, inhibiting cell proliferation and survival in osteosarcoma 
A

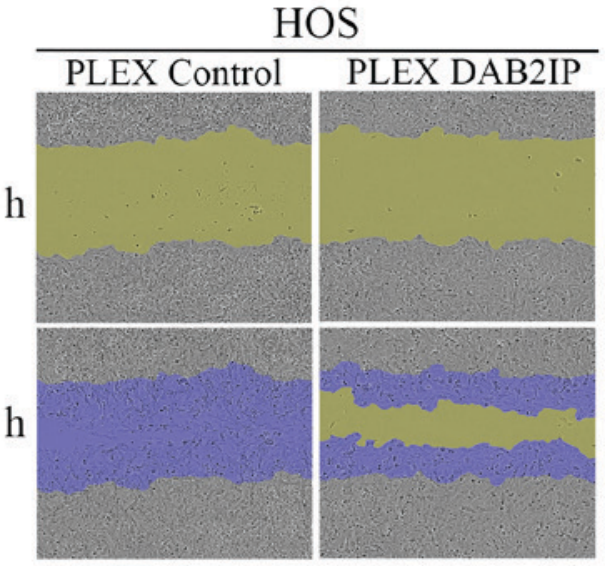

$\mathrm{B}$

hFOB
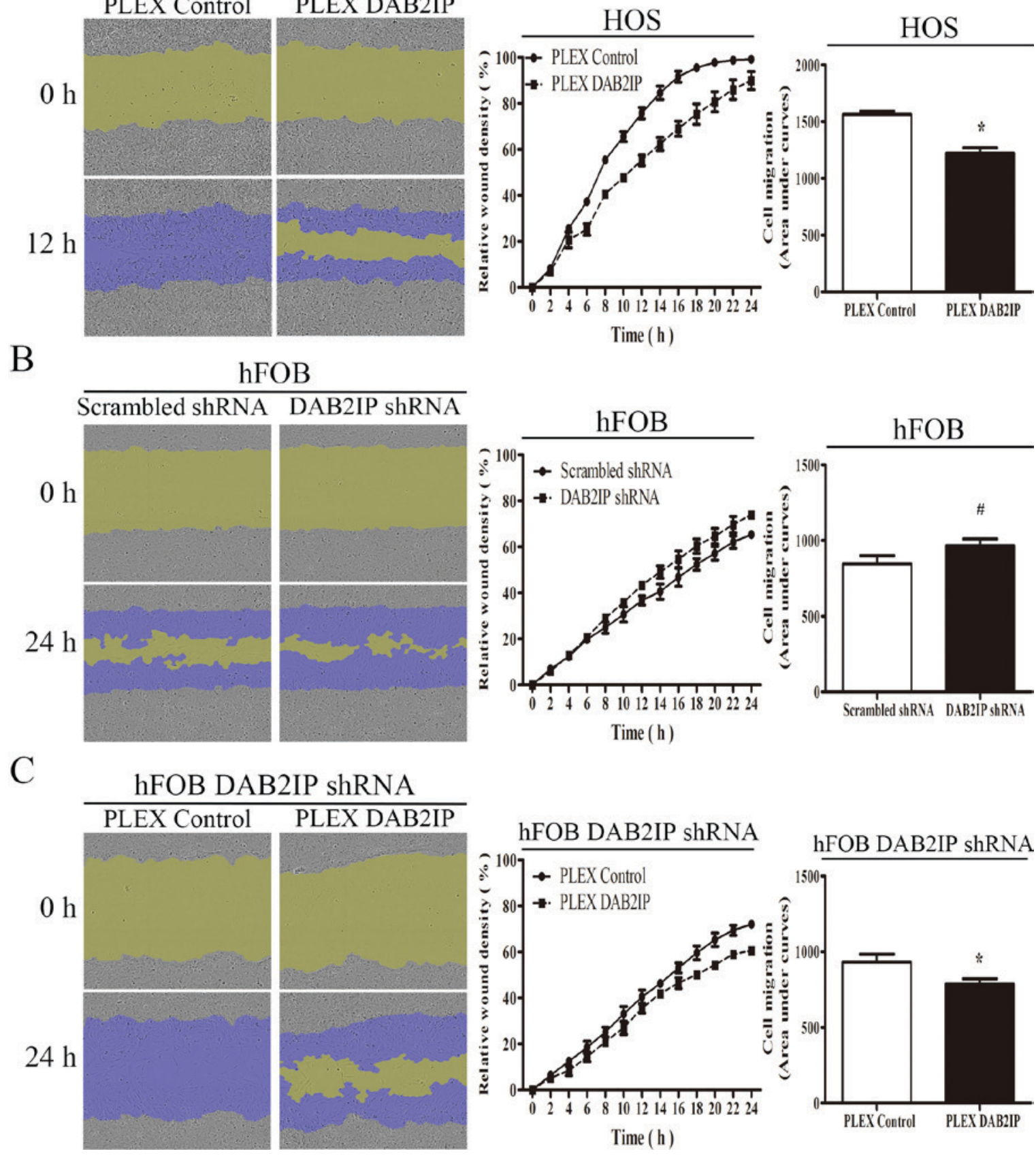

Figure 5. Effects of DAB2IP expression on cell migration of osteosarcoma cells and normal osteoblasts. The effect of DAB2IP expression on the migration of (A) osteosarcoma HOS cells, (B) hFOB 1.19 osteoblasts and (C) hFOB 1.19 pLEX DAB2IP cells was determined using the scratch wound healing assay. Representative images of cell migration are on the left and the time course of cell migration and area under curve analysis are on the right. All results are representative of three independent experiments. ${ }^{*} \mathrm{P}<0.05$, comparing HOS PLEX control cells with HOS PLEX DAB2IP cells. " $\mathrm{P}<0.05$, comparing hFOB Scrambled shRNA cells with hFOB DAB2IP shRNA cells. "P $<0.05$, comparing hFOB DAB2IP shRNA PLEX control cells with hFOB DAB2IP shRNA PLEX DAB2IP cells. DAB2IP, disabled homolog 2 interactive protein; pLEX DAB2IP, cells transfected with plasmid expressing DAB2IP; shRNA, short hairpin RNA.

cells and osteoblasts by inducing apoptosis and a greater G0/G1-phase distribution. Additionally, the expression of DAB2IP may inhibit the migration and invasion of osteosarcoma cells and normal osteoblasts. The identification of these roles for DAB2IP in osteosarcoma may be beneficial, enriching the understanding of the mechanism of osteosarcoma progression, and possibly providing an approach for the early detection of osteosarcoma and novel therapeutic modalities.

\section{Acknowledgements}

Not applicable.

\section{Funding}

The present study was supported by the National Natural Science Foundation of China (grant nos. 81472999 and 81272350), the Key Natural Science Foundation of 
A
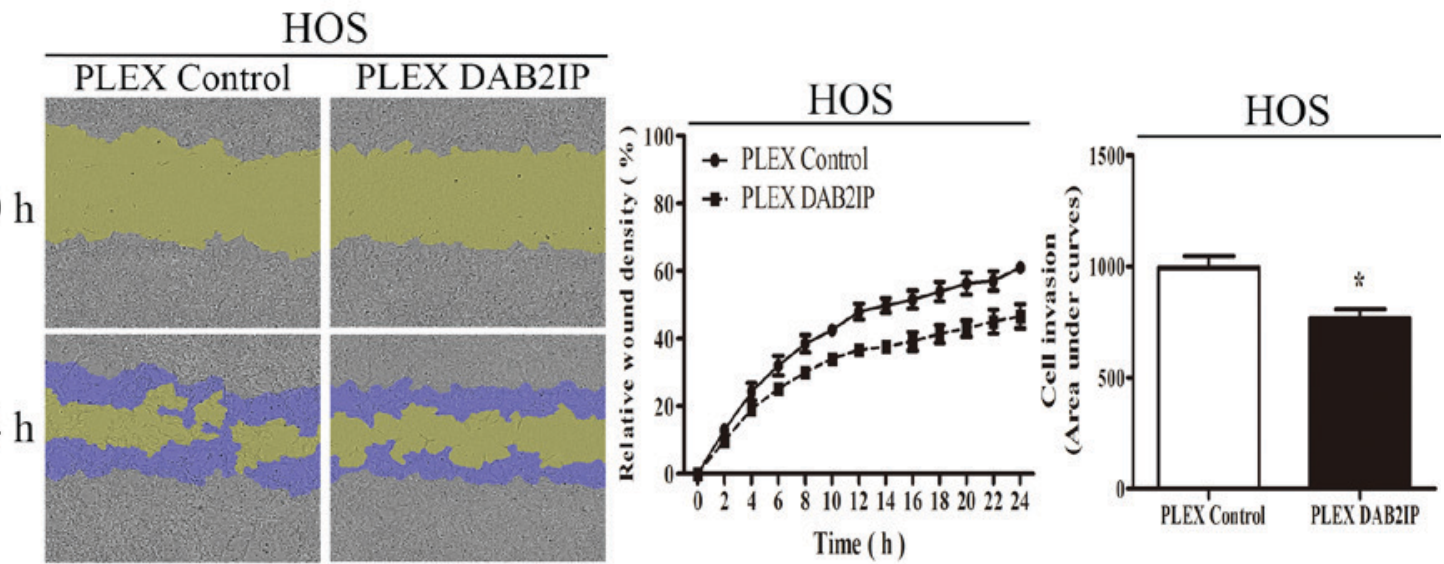

$\mathrm{B}$

\section{$\mathrm{hFOB}$}
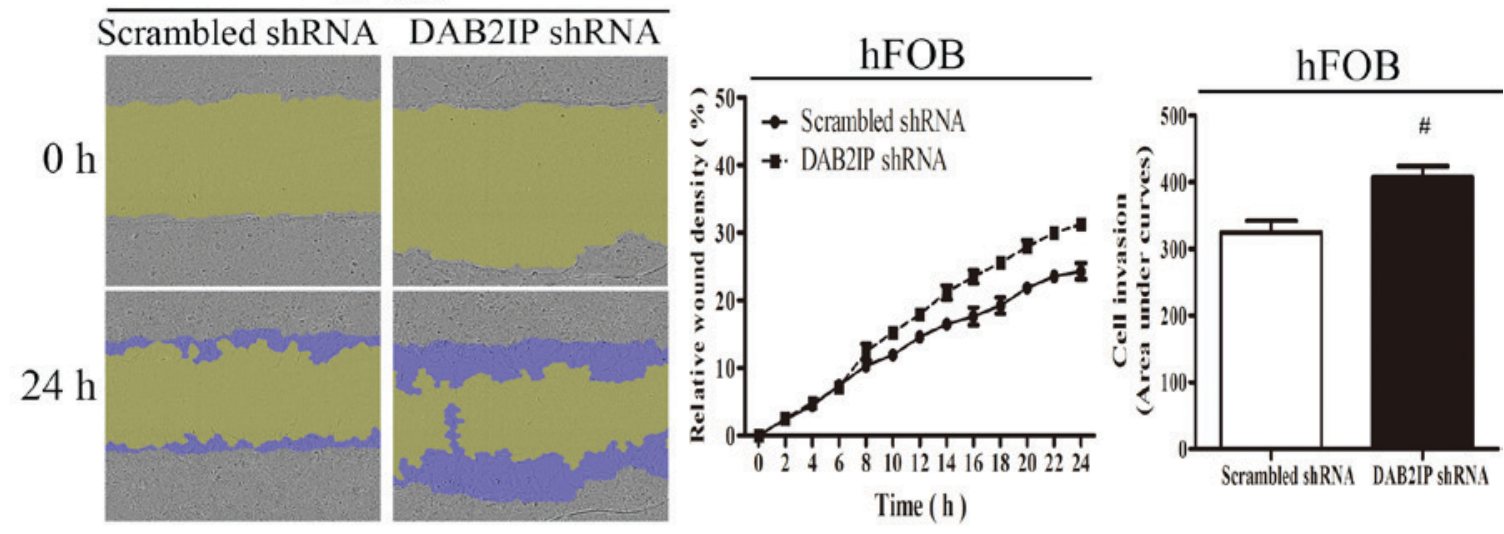

C

hFOB DAB2IP ShRNA
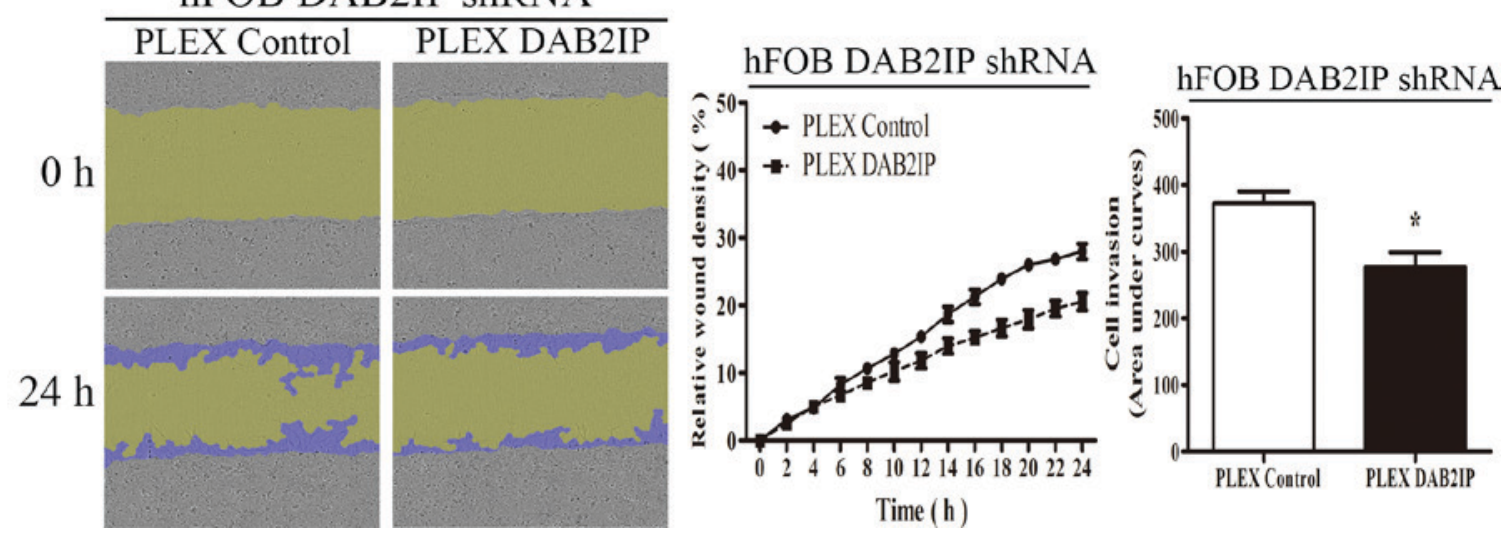

Figure 6. Effects of DAB2IP on cell invasion of osteosarcoma cells and normal osteoblasts. The effect of DAB2IP expression on the invasion of (A) osteosarcoma HOS cells (B) hFOB 1.19 osteoblasts and (C) hFOB 1.19 pLEX DAB2IP cells was determined by an invasion assay. Representative images of cell migration are on the left and the time course of cell migration and area under curve analysis are on the right. All results are representative of three independent experiments. "P $<0.05$, comparing HOS PLEX control cells with HOS PLEX DAB2IP cells. " $\mathrm{P}<0.05$, comparing hFOB Scrambled shRNA cells with hFOB DAB2IP shRNA cells. "P<0.05, comparing hFOB DAB2IP shRNA PLEX control cells with hFOB DAB2IP shRNA PLEX DAB2IP cells. DAB2IP, disabled homolog 2 interactive protein; pLEX DAB2IP, cells transfected with plasmid expressing DAB2IP; shRNA, short hairpin RNA.

Guangdong (grant no. 2015A030311038) and the Science and Technology Planning Project of Guangdong Province (grant no. 2014A020212064).

\section{Availability of data and materials}

The datasets used and analyzed during the current study are available from the corresponding author on reasonable request.

\section{Authors' contributions}

$\mathrm{JH}$ conducted the experiments and participated in analyzing the experiment data, and also was a major contributor in writing the manuscript. SH participated in analyzing the experiment data particularly the cell migration and invasion assay, and also participated in writing the manuscript. ZL, JZ and JS participated in performing the experiment and analyzing the experiment data. WJ and XL designed the experiment and 
participated in analyzing the experiment data particularly the cell cycle assay and the cell apoptosis assay, and also participated in writing the manuscript. All authors read and approved the final manuscript.

\section{Ethics approval and consent to participate}

Not applicable.

\section{Consent for publication}

Not applicable.

\section{Competing interests}

The authors declare that there are no competing interests.

\section{References}

1. Ottaviani G and Jaffe N: The epidemiology of osteosarcoma. Cancer Treat Res 152: 3-13, 2009.

2. Tan ML, Choong PF and Dass CR: Osteosarcoma: Conventional treatment vs. Gene therapy. Cancer Biol Ther 8: 106-117, 2009.

3. Broadhead ML, Clark JC, Myers DE, Dass CR and Choong PF: The molecular pathogenesis of osteosarcoma: A review. Sarcoma 2011: 959248, 2011.

4. He JP, Hao Y, Wang XL, Yang XJ, Shao JF, Guo FJ and Feng JX: Review of the molecular pathogenesis of osteosarcoma. Asian Pac J Cancer Prev 15: 5967-5976, 2014.

5. Chen H, Pong RC, Wang Z and Hsieh JT: Differential regulation of the human gene DAB2IP in normal and malignant prostatic epithelia: Cloning and characterization. Genomics 79: 573-581, 2002.

6. Wang Z, Tseng CP, Pong RC, Chen H, McConnell JD, Navone N and Hsieh JT: The mechanism of growth-inhibitory effect of DOC-2/DAB2 in prostate cancer. Characterization of a novel GTPase-activating protein associated with $\mathrm{N}$-terminal domain of DOC-2/DAB2. J Biol Chem 277: 12622-12631, 2002.

7. Zhang R, He X, Liu W, Lu M, Hsieh JT and Min W: AIP1 mediates TNF-alpha-induced ASK1 activation by facilitating dissociation of ASK1 from its inhibitor 14-3-3. J Clin Invest 111: 1933-1943, 2003

8. Dote H, Toyooka S, Tsukuda K, Yano M, Ouchida M, Doihara H, Suzuki M, Chen H, Hsieh JT, Gazdar AF and Shimizu N: Aberrant promoter methylation in human DAB2 interactive protein (hDAB2IP) gene in breast cancer. Clin Cancer Res 10: 2082-2089, 2004.

9. Dote H, Toyooka S, Tsukuda K, Yano M, Ota T, Murakami M, Naito M, Toyota M, Gazdar AF and Shimizu N: Aberrant promoter methylation in human DAB2 interactive protein (hDAB2IP) gene in gastrointestinal tumour. Br J Cancer 92: 1117-1125, 2005.

10. Yano M, Toyooka S, Tsukuda K, Dote H, Ouchida M, Hanabata T, Aoe M, Date H, Gazdar AF and Shimizu N: Aberrant promoter methylation of human DAB2 interactive protein (hDAB2IP) gene in lung cancers. Int J Cancer 113: 59-66, 2005.

11. Qiu GH, Xie H, Wheelhouse N, Harrison D, Chen GG Salto-Tellez M, Lai P, Ross JA and Hooi SC: Differential expression of hDAB2IPA and hDAB2IPB in normal tissues and promoter methylation of hDAB2IPA in hepatocellular carcinoma. J Hepatol 46: 655-663, 2007.

12. Smits M, van Rijn S, Hulleman E, Biesmans D, van Vuurden DG, Kool M, Haberler C, Aronica E, Vandertop WP, Noske DP and Würdinger T: EZH2-regulated DAB2IP is a medulloblastoma tumor suppressor and a positive marker for survival. Clin Cancer Res 18: 4048-4058, 2012.

13. Zhang X, Li N, Li X, Zhao W, Qiao Y, Liang L and Ding Y: Low expression of DAB2IP contributes to malignant development and poor prognosis in hepatocellular carcinoma. J Gastroenterol Hepatol 27: 1117-1125, 2012

14. Duan YF, Li DF, Liu YH, Mei P, Qin YX, Li LF, Lin QX and Li ZJ: Decreased expression of DAB2IP in pancreatic cancer with wild-type KRAS. Hepatobiliary Pancreat Dis Int 12: 204-209, 2013
15. Shen YJ, Kong ZL, Wan FN, Wang HK, Bian XJ, Gan HL, Wang CF and Ye DW: Downregulation of DAB2IP results in cell proliferation and invasion and contributes to unfavorable outcomes in bladder cancer. Cancer Sci 105: 704-712, 2014

16. Min J, Liu L, Li X, Jiang J, Wang J, Zhang B, Cao D, Yu D, Tao D, Hu J, et al: Absence of DAB2IP promotes cancer stem cell like signatures and indicates poor survival outcome in colorectal cancer. Sci Rep 5: 16578, 2015.

17. Min W, Lin Y, Tang S, Yu L, Zhang H, Wan T, Luhn T, Fu H and Chen H: AIP1 recruits phosphatase PP2A to ASK1 in tumor necrosis factor-induced ASK1-JNK activation. Circ Res 102: 840-848, 2008

18. Xie D, Gore C, Zhou J, Pong RC, Zhang H, Yu L, Vessella RL Min W and Hsieh JT: DAB2IP coordinates both PI3K-Akt and ASK1 pathways for cell survival and apoptosis. Proc Natl Acad Sci USA 106: 19878-8383, 2009.

19. Xie D, Gore C, Liu J, Pong RC, Mason R, Hao G, Long M, Kabbani W, Yu L, Zhang H, et al: Role of DAB2IP in modulating epithelial-to-mesenchymal transition and prostate cancer metastasis. Proc Natl Acad Sci USA 107: 2485-2490, 2010.

20. Kong Z, Xie D, Boike T, Raghavan P, Burma S, Chen DJ, Habib AA, Chakraborty A, Hsieh JT and Saha D: Downregulation of human DAB2IP gene expression in prostate cancer cells results in resistance to ionizing radiation. Cancer Res 70: 2829-2839, 2010.

21. Wu K, Xie D, Zou Y, Zhang T, Pong RC, Xiao G, Fazli L, Gleave M, He D, Boothman DA and Hsieh JT: The mechanism of DAB2IP in chemoresistance of prostate cancer cells. Clin Cancer Res 19: 4740-4749, 2013.

22. Wu K, Wang B, Chen Y, Zhou J, Huang J, Hui K, Zeng J, Zhu J, Zhang $\mathrm{K}, \mathrm{Li} \mathrm{L}$, et al: DAB2IP regulates the chemoresistance to pirarubicin and tumor recurrence of non-muscle invasive bladder cancer through STAT3/Twist1/P-glycoprotein signaling. Cell Signal 27: 2515-2523, 2015

23. Zhang T, Shen Y, Chen Y, Hsieh JT and Kong Z: The ATM inhibitor KU55933 sensitizes radioresistant bladder cancer cells with DAB2IP gene defect. Int J Radiat Biol 91: 368-378, 2015.

24. Zhang H, Zhang R, Luo Y, D'Alessio A, Pober JS and Min W: AIP1/DAB2IP, a novel member of the Ras-GAP family, transduces TRAF2-induced ASK1-JNK activation. J Biol Chem 279: 44955-49965, 2004.

25. Lee GH, Kim SH, Homayouni R and D'Arcangelo G: Dab2ip regulates neuronal migration and neurite outgrowth in the developing neocortex. PLoS One 7: e46592, 2012.

26. Harrison SC, Cooper JA, Li K, Talmud PJ, Sofat R, Stephens JW, Hamsten A; HIFMECH Consortium, Sanders J, Montgomery $\mathrm{H}$, et al: Association of a sequence variant in DAB2IP with coronary heart disease. Eur Heart J 33: 881-888, 2012.

27. Zhang J, Zhou HJ, Ji W and Min W: AIP1-mediated stress signaling in atherosclerosis and arteriosclerosis. Curr Atheroscler Rep 17: 503, 2015.

28. Zhang H, He Y, Dai S, Xu Z, Luo Y, Wan T, Luo D, Jones D, Tang S, Chen H, et al: AIP1 functions as an endogenous inhibitor of VEGFR2-mediated signaling and inflammatory angiogenesis in mice. J Clin Invest 118: 3904-3916, 2008.

29. Qiao S, Kim SH, Heck D, Goldowitz D, LeDoux MS and Homayouni R: Dab2IP GTPase activating protein regulates dendrite development and synapse number in cerebellum. PLoS One 8: e53635, 2013.

30. Yun EJ, Baek ST, Xie D, Tseng SF, Dobin T, Hernandez E, Zhou J, Zhang L, Yang J, Sun H, et al: DAB2IP regulates cancer stem cell phenotypes through modulating stem cell factor receptor and ZEB1. Oncogene 34: 2741-2752, 2015.

31. Thery C, Amigorena S, Raposo G and Clayton A: Isolation and characterization of exosomes from cell culture supernatants and biological fluids. Curr Protoc Cell Biol Chapter 3: Unit 3.22, 2006.

32. Salomon C, Ryan J, Sobrevia L, Kobayashi M, Ashman K, Mitchell $\mathrm{M}$ and Rice GE: Exosomal signaling during hypoxia mediates microvascular endothelial cell migration and vasculogenesis. PLoS One 8: e68451, 2013.

33. Kobayashi M, Salomon C, Tapia J, Illanes SE, Mitchell MD and Rice GE: Ovarian cancer cell invasiveness is associated with discordant exosomal sequestration of Let-7 miRNA and miR-200. J Transl Med 12: 4, 2014.

34. Chen H, Toyooka S, Gazdar AF and Hsieh JT: Epigenetic regulation of a novel tumor suppressor gene (hDAB2IP) in prostate cancer cell lines. J Biol Chem 278: 3121-3130, 2003. 
35. Chen H, Tu SW and Hsieh JT: Down-regulation of human DAB2IP gene expression mediated by polycomb Ezh2 compLEX and histone deacetylase in prostate cancer. J Biol Chem 280 22437-22444, 2005

36. Duggan D, Zheng SL, Knowlton M, Benitez D, Dimitrov L, Wiklund F, Robbins C, Isaacs SD, Cheng Y, Li G, et al: Two genome-wide association studies of aggressive prostate cancer implicate putative prostate tumor suppressor gene DAB2IP. J Natl Cancer Inst 99: 1836-1844, 2007.

37. Liu K, He Q, Liao G and Han J: Identification of critical genes and gene interaction networks that mediate osteosarcoma metastasis to the lungs. Exp Ther Med 10: 1796-1806, 2015.

38. Shi R, Li J, Tang F, Luo YI and Tu CQ: Identification and functional study of osteosarcoma metastasis marker genes. Oncol Lett 10: 1848-1852, 2015.

39. Yang L, Liu ZM, Rao YW, Cui SQ, Wang H and Jia XJ: Downregulation of microRNA-586 inhibits proliferation, invasion and metastasis and promotes apoptosis in human osteosarcoma U2-OS cell line. Cytogenet Genome Res 146: 268-278, 2015.
40. Xu J, Wan P, Wang M, Zhang J, Gao X, Hu B, Han J, Chen L, Sun K, Wu J, et al: AIP1-mediated actin disassembly is required for postnatal germ cell migration and spermatogonial stem cell niche establishment. Cell Death Dis 6: e1818, 2015.

41. Min J, Zaslavsky A, Fedele G, McLaughlin SK, Reczek EE, De Raedt T, Guney I, Strochlic DE, Macconaill LE, Beroukhim R, et al: An oncogene-tumor suppressor cascade drives metastatic prostate cancer by coordinately activating Ras and nuclear factor-kappaB. Nat Med 16: 286-294, 2010.

42. Ji W, Li Y, He Y, Yin M, Zhou HJ, Boggon TJ, Zhang H and Min W: AIP1 expression in tumor niche suppresses tumor progression and metastasis. Cancer Res 75: 3492-3504, 2015.

cC) (i) $\Theta$ This work is licensed under a Creative Commons Attribution-NonCommercial-NoDerivatives 4.0 International (CC BY-NC-ND 4.0) License. 